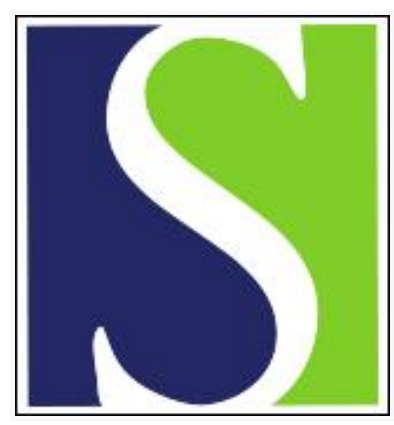

Scand J Work Environ Health 2000;26(3):263-272

https://doi.org/10.5271/sjweh.541

Issue date: Jun 2000

Item bias in indices measuring psychosocial work environment and health

by Ørhede E, Kreiner S

The following article refers to this text: 2003;29(6):444-451

Key terms: construct validity; differential item functioning; index; scale

This article in PubMed: www.ncbi.nlm.nih.gov/pubmed/10901120

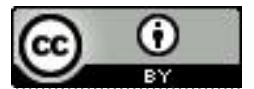




\title{
Item bias in indices measuring psychosocial work environment and health
}

\author{
by Elsa Ørhede, PhD, ${ }^{1}$ Svend Kreiner, MSC ${ }^{2}$
}

\author{
Ørhede E, Kreiner S. Item bias in indices measuring psychosocial work environment and health. Scand J Work \\ Environ Health 2000;26(3);263-272.
}

\begin{abstract}
Objectives The main purpose of this study was to demonstrate the relevance of testing indices concerning the psychosocial work environment by item bias or differential item functioning (DIF) analysis. Especially when the work environment for different groups is compared, this kind of construct validation is important. As exogenous variables gender, age, and occupational group were selected.

Methods Data were taken from a cross-sectional study of Danish employees aged $19-59$ years ( $N=5940)$. The study was carried out in 1990 and followed-up in 1995.

Results Item bias was demonstrated in all indices when analyzed in relation to gender, age, and occupational groups of the total population. Item bias was much weaker or disappeared as the population was divided into main occupational groups and analyzed in relation to the same exogenous variables.

Conclusions For a heterogeneous group of employees, gender, age, and occupational status are significant determinants of the response pattern in relation to indices of the psychosocial work environment. It was concluded that, if the psychosocial work environment for different groups is to be compared, indices should always be tested for item bias in relation to the exogenous variables included in the final analyses. Indices should only be used if there is no item bias. If such indices cannot be constructed, it is suggested that researchers either concentrate on constructing indices that are valid in subgroups or report results based on single-item analyses.
\end{abstract}

Key terms construct validity, differential item functioning, index, scale.

Within recent decades the number of studies of psychological and social factors has increased considerably. Changes in the labor market in many industrialized countries, especially the introduction of new technologies, have caused fundamental changes in the work environment. The focus in many studies of the work environment has, to a certain extent, shifted from traditional physical and chemical factors to psychological and social factors at work and the health effects related to exposure to these factors. Within research on psychological and social factors at work, several theories and models have been developed ( $1-5)$. The job-strain theory first published by Karasek (3) and later revised by Karasek \& Theorell (4) has had great impact on research in the past 20 years. Depending on whether the intensity of the exposure factors is high or low, the theory points out how the relations between demands, control, and social support at work and some health outcomes like stress and cardiovascular disease change. High demands and low control at work is, for example, a risk combination for stress or heart disease. The psychosocial variables used in the current study originally come from a joint Nordic questionnaire on work conditions and health developed through Nordic cooperation in 1984-1988 (6). The concepts of the job-strain model evidently inspired the development of the psychosocial questions included in the questionnaire.

Data concerning psychological and social factors at work are often collected by survey methods $(7,8)$. It is common practice to construct indices by summating answers to questions measuring a certain concept from survey data. The purpose of summating answers into indices is to make the analysis simpler than with single items by introducing a construct that expresses the content of the latent parameter or concept. The assumption of a latent parameter underlying several items is essential when indices are constructed (9). Another important requirement is that an index not lose any information when compared with the information of single-item response patterns.

In psychometrics exploratory factor analysis, item response modeling, and confirmatory factor analysis have been the most used techniques for index construction. A single summary index requires that items be shown

1 National Institute of Occupational Health, Copenhagen, Denmark.

2 Department of Biostatistics, University of Copenhagen, Copenhagen, Denmark.

Reprint requests to: Dr Elsa Ørhede, National Institute of Occupational Health, Lersø Park Allé 105, DK-2100 Copenhagen, Denmark. [E-mail: eoe@ami.dk] 
unidimensionally in the sense that they only depend on 1 single latent variable. One important problem with both factor analyses and general item response models is however that unidimensionality is not sufficient to ensure that information from the items constituting the factor is still maintained in any simple weighted or unweighted summary score. If information is lost or biased the construct validity of the index measuring the factor is poor.

Criteria-related construct validity, as it is commonly understood $(10,11)$, implies various things. First, it implies that items are correlated because they all depend on one and the same latent variable representing the theoretical construct. Second, it implies that items only correlate with other variables because the latent variable correlates with these variables. For a set of items to be construct valid it is required that the items be both locally independent in the sense that (i) items are conditionally independent given the latent variable and (ii) that items and exogenous variables be conditionally independent given the latent variable.

In many clinical and statistical situations it is necessary to use the summary score as a proxy for the latent variable as statistical programs for the analysis of data by latent structure models are either not available or practical. In such cases the aforementioned requirements can be strengthened by the stronger requirement that items must also be conditionally independent of all other variables given the summary score. This requirement will hereafter be referred to as a requirement defining a construct-valid index scale.

\section{Item bias or differential item functioning}

An analysis of item bias or differential item functioning (DIF) relative to a summary index is one way to analyze the construct validity of the index further. The concepts and techniques underlying the analysis originate in psychometrics where the analysis is performed to reveal whether information from an index consisting of several items is inadequate and maybe distorted in the sense that important information may be lost if responses from separate items are not taken into account.

Item bias (as called hereafter) can be formally defined as follows: an item in an index is biased if all respondents at a given level of the attribute measured (at a given index score) do not have equal probability of scoring positively on the item regardless of subgroup membership like gender, age group, or occupational group (12). Differiential Item Functioning, edited by Holland \& Wainer (13), can be referred to for a comprehensive discussion of concepts and techniques underlying analyses of item bias.
To some extent item bias analysis has also been adopted in medical research $(9,14)$. The aim of our study was to show the relevance of analyzing psychosocial indices for item bias. Especially when being used to compare the work environment of different occupational groups by means of index scales, item bias analysis is relevant. Groups of employees who, in relation to the index, seem to be quantitatively equal because they are in the same score group may be qualitatively different because they have given different answers to the items that constitute the index. False interpretations of or conclusions that the psychosocial work environment of the groups compared might incidentally be the consequence.

\section{Subjects and methods}

A cross-sectional study of the work environment was performed among Danish employees in 1990. The study included 5940 employees (3097 men, 2843 women) aged 19 to 59 years. Data were collected by telephone interview, and the response rate was $89.7 \%$. The questionnaire used in the survey was, to a large extent, based on a questionnaire developed in a Nordic project 19841988 (6). The Nordic Questionnaire on Working Conditions and Health included 104 questions concerning the following issues: (i) physical or chemical exposure, (ii) ergonomic exposure, (iii) psychological and social factors, (iv) work accidents, (v) stress and psychosomatic symptoms, and (vi) somatic health symptoms. The questionnaire included 39 items about psychological and social factors primarily based on a Swedish model (2). The items were related to several dimensions of the psychosocial work environment (eg, qualitative and quantitative demands at work, autonomy and possibilities of development, and social support). For each issue, indices were constructed by summing the answers of the items into an index.

In 1995, a follow-up study of the population was carried out. The same questions were used, and identical indices were constructed, except for the stress index, in which some slight changes had occurred. This study was based on analyses carried out on the data from 1990 as the 1995 data were not available when the analyses were first performed.

The following indices were constructed for the analysis: (i) demand factor ( 3 items), (ii) autonomy factor (4 items), (iii) development factor (4 items), (iv) social support from colleagues (4 items), (v) social support from superiors (2 items), (vi) stress factor ( 7 items), and (vii) psychosomatic factor (5 items).

A list of the questions and response categories is included in the appendix. 


\section{Analysis of item bias}

The basic test of item bias is a test of conditional independence. If items and exogenous variables are categorical variables, these tests can be performed as the chisquare test in 3-way tables. If items and exogenous variables are ordinal or binary the power of the tests can be increased by test statistics addressing monotone relationships among the variables. In this paper the partial gamma-coefficient, a partial correlation coefficient for ordinal categorical variables as discussed by Agresti (15), is used. The P-values reported for both the chi-square test statistics and the gamma coefficients are Monte Carlo estimates of exact conditional P-values as described by Kreiner (16).

A large number of tests for conditional independence is required by item bias analysis, in most cases, generate multiple testing problems in the sense that significant results can appear with a nonimmaterial probability for purely random reasons if the overall level of significance is high. Standard Bonferroni techniques adjusting the obtained levels of significance can however not be used as test results since different hypotheses of no item bias are highly correlated. Instead of attempting a formal adjustment of P-values, we distinguished between indisputable evidence of item bias where P-values were less than 0.0005 and dubious evidence where $P$-values may have been significant according to the standard $5 \%$ level of significance. In the absence of formal rules for adjusting $\mathrm{P}$-values, an unarguable conclusion in favor of item bias would require at least some indisputable significant $P$. values.

All the indices were tested for item bias in relation to the exogenous variables gender, age, and occupational group. These variables were assessed to be the most relevant exogenous variables for the analyses of the psychosocial work environment: gender because men and women have, to a great extent, different occupations, age because different age groups often have a different view of the work environment, and occupational group because the work environment clearly varies within different occupations.

\section{Results}

Initially, an analysis was made on the total data set (5940 respondents). All the indices were tested for item bias using gender as the exogenous variable. For some of the analyses only the "demand index" was used as our "case" to exemplify the process of item bias analyses and to avoid exaggerating the amount of information.

The indices were summated so that high values meant high exposure and low values meant low exposure.

The distribution of the men and women in the score groups of the demand index is shown in table 1 . There is significant difference in the distribution of the men and women. Men generally felt more exposed to high demands than women did.

Table 2 shows the distribution of the total population in the score groups of the demand index and age groups. The youngest employees felt more exposed to low demands than all other age groups. Tables 1 and 2 show that the indices differentiated the work environment well for both the men and women and for the age groups.

In table 3 the results of the item bias analyses for all the exposure indices are shown in relation to age and gender. According to the demand index there was indisputable evidence of bias for all 3 items in relation to gender. The P-values were so low that test results of this kind would not be expected even in connection with multiple testing procedures.

The results imply that the demand index did not work in the same way for the men and women when they were

Table 1. Distribution of the men and women according to the score groups of the demand index. (bold $=$ significant $P$-value)

\begin{tabular}{lrrr}
\hline Demand index & $\begin{array}{c}\text { Male } \\
(\%)\end{array}$ & $\begin{array}{c}\text { Female } \\
(\%)\end{array}$ & $\begin{array}{r}\text { Total } \\
\text { number }\end{array}$ \\
\hline Score groups 0-3 (very low demand) & 20.1 & 23.2 & 1284 \\
Score groups 4-5 (low demand) & 21.3 & 25.0 & 1369 \\
Score groups 6-7 (average demand) & 16.2 & 16.1 & 960 \\
Score groups 8-10 (high demand) & 28.8 & 24.4 & 1585 \\
Score groups 11-15 (very high demand) & 13.6 & 11.3 & 742 \\
Total number & 3097 & 2843 & 5940
\end{tabular}

$P=\mathbf{0 . 0 0 0 0}$ Gamma $=-0.09794$

Table 2. Distribution of the respondents according to the demand index in the score and age groups. (bold = significant P-value)

\begin{tabular}{|c|c|c|c|c|c|c|}
\hline Demand index & $\begin{array}{c}\leq 19 \text { years } \\
(\%)\end{array}$ & $\begin{array}{c}20-29 \text { years } \\
(\%)\end{array}$ & $\begin{array}{c}30-39 \text { years } \\
(\%)\end{array}$ & $\begin{array}{c}40-49 \text { years } \\
(\%)\end{array}$ & $\begin{array}{c}50-59 \text { years } \\
(\%)\end{array}$ & Total number \\
\hline Score groups $1-3$ (very low demand) & 33.5 & 25.2 & 16.1 & 20.5 & 24.0 & 1284 \\
\hline Score groups $4-5$ (low demand) & 28.7 & 22.8 & 22.7 & 21.5 & 25.1 & 1369 \\
\hline Score groups $6-7$ (average demand) & 14.3 & 16.0 & 16.8 & 15.5 & 16.8 & 960 \\
\hline Score groups $-8-10$ (high demand) & 20.9 & 26.7 & 29.6 & 27.4 & 22.1 & 1585 \\
\hline Score groups $11-15$ (very high demand) & 2.6 & 9.3 & 14.8 & 15.1 & 12.0 & 742 \\
\hline Total number & 230 & 1568 & 1609 & 1571 & 962 & 5940 \\
\hline
\end{tabular}

$\mathrm{P}=\mathbf{0 . 0 0 0 0}$ Gamma $=0.04309$ 
Table 3. Item bias in relation to gender and age in the indices for the total population $(N=1990)$ for the items in the demand index, the autonomy index, the development index, the social support from colleagues index, and the social support from superiors index. $\left(X^{2}=\right.$ chi-square,$d f=$ degrees of freedom, bold $=$ significant P-value)

\begin{tabular}{|c|c|c|c|c|c|c|}
\hline Index & $x^{2}$ & $d f$ & $\underset{P}{\text { Exact }}$ & Gamma & $\begin{array}{c}\text { Exact } \\
P\end{array}$ & $\begin{array}{c}\text { Total } \\
\text { number }\end{array}$ \\
\hline \multicolumn{7}{|l|}{ Demand } \\
\hline \multicolumn{7}{|l|}{ Work load } \\
\hline Gender & 233.6 & 50 & 0.000 & 0.26 & 0.000 & \multirow{2}{*}{5927} \\
\hline Age & 38.5 & 48 & 0.834 & 0.04 & 0.280 & \\
\hline \multicolumn{7}{|c|}{ Concentration demand } \\
\hline Gender & 200.2 & 47 & 0.000 & 0.30 & 0.000 & \multirow[t]{2}{*}{5927} \\
\hline Age & 48.2 & 45 & 0.332 & -0.06 & 0.280 & \\
\hline \multicolumn{7}{|c|}{ Risk demand } \\
\hline Gender & 437.6 & 50 & 0.000 & -0.45 & 0.000 & \multirow[t]{2}{*}{5927} \\
\hline Age & 51.2 & 48 & 0.348 & -0.01 & 0.432 & \\
\hline \multicolumn{7}{|l|}{ Autonomy } \\
\hline Work tem & & & & & & \\
\hline Gender & 91.6 & 45 & 0.002 & -0.20 & 0.000 & \multirow{2}{*}{5922} \\
\hline Age & 71.8 & 45 & 0.023 & -0.31 & 0.000 & \\
\hline \multicolumn{7}{|c|}{ Organizing own work } \\
\hline Gender & 37.9 & 33 & 0.257 & 0.09 & 0.000 & \multirow[t]{2}{*}{5922} \\
\hline Age & 96.1 & 33 & 0.000 & 0.49 & 0.000 & \\
\hline \multicolumn{7}{|c|}{ Decide the solution of work tasks } \\
\hline Gender & 41.1 & 32 & 0.120 & 0.07 & 0.010 & \multirow[t]{2}{*}{5922} \\
\hline Age & 34.2 & 32 & 0.400 & -0.06 & 0.233 & \\
\hline \multicolumn{7}{|c|}{ Obtain information about decisions } \\
\hline Gender & 59.6 & 33 & 0.013 & 0.09 & 0.000 & \multirow[t]{2}{*}{5922} \\
\hline Age & 35.1 & 33 & 0.363 & -0.11 & 0.065 & \\
\hline \multicolumn{7}{|c|}{ Development at work } \\
\hline Too diffich & ult tasks & & & & & \multirow{3}{*}{5911} \\
\hline Gender & 57.8 & 52 & 0.243 & 0.10 & 0.000 & \\
\hline Age & 134.0 & 52 & 0.000 & -0.33 & 0.000 & \\
\hline \multicolumn{7}{|c|}{ Repeating the same tasks } \\
\hline $\begin{array}{l}\text { Gender } \\
\text { Age }\end{array}$ & $\begin{array}{r}59.1 \\
130.3\end{array}$ & $\begin{array}{l}55 \\
55\end{array}$ & $\begin{array}{l}0.340 \\
0.000\end{array}$ & $\begin{array}{r}-0.10 \\
0.25\end{array}$ & $\begin{array}{l}0.000 \\
0.000\end{array}$ & 5911 \\
\hline Possibility & t to learr & w tas & & & & \\
\hline Gender & 32.5 & 39 & 0.752 & 0.01 & 0.352 & 5911 \\
\hline Age & 38.1 & 39 & 0.430 & -0.27 & 0.000 & \\
\hline Variation I & in work & & & & & \\
\hline Gender & 38.1 & 39 & 0.507 & 0.01 & 0.357 & 5911 \\
\hline Age & 89.9 & 39 & 0.005 & 0.40 & 0.000 & \\
\hline $\begin{array}{l}\text { Social supp } \\
\text { Isolated W }\end{array}$ & $\begin{array}{l}\text { ort from } \\
\text { vork }\end{array}$ & Ileagu & & & & \\
\hline Gender & 74.1 & 28 & 0.000 & 0.15 & 0.000 & 5630 \\
\hline Age & 38.8 & 24 & 0.068 & -0.35 & 0.000 & \\
\hline Possibility & for hell & dd ad & & & & \\
\hline Gender & 30.4 & 33 & 0.647 & 0.04 & 0.145 & 5630 \\
\hline Age & 37.5 & 27 & 0.127 & -0.06 & 0.325 & 0.325 \\
\hline Support $f_{t}$ & rom coll & ues & & & & \\
\hline Gender & 75.7 & 32 & 0.002 & 0.14 & 0.002 & 5630 \\
\hline Age & 27.3 & 27 & 0.398 & 0.00 & 0.515 & 0.515 \\
\hline Possibility & t to talk & ing $w$ & chours & & & \\
\hline Gender & 126.1 & 41 & 0.000 & -0.24 & 0.000 & 5630 \\
\hline Age & 46.1 & 34 & 0.138 & 0.26 & 0.000 & 0.000 \\
\hline Social supp & ort from & periol & & & & \\
\hline Support ff & rom sup & & & & & \\
\hline Gender & 8.9 & 9 & 0.452 & -0.07 & 0.030 & 5927 \\
\hline Age & 17.0 & 9 & 0.058 & 0.17 & 0.032 & \\
\hline Positive fe & ed back & & & & & \\
\hline Gender & 8.9 & 9 & 0.450 & -0.07 & 0.035 & 5927 \\
\hline Age & 17.0 & 9 & 0.068 & 0.17 & 0.032 & \\
\hline
\end{tabular}

at the same score group level. Comparisons of work demands for the men and women would therefore be inadequate if the comparison were based only on the summary index score. The men and women at the same score group level seemed to experience different demands in their work. Therefore it would not be correct to conclude that there were no gender differences even if the men and women did not differ with respect to the distributions of the index. An analysis of the demand index in relation to occupational groups led to identical results (table not shown).

In the presence of a monotone relationship between an item and an exogenous variable, the values of the gamma coefficients tell how the groups, defined by the levels of the exogenous variables, differ. Positive gamma values for the first 2 items and a negative gamma value for the 3 rd item of the demand scale indicated that the men and women with the same overall index score were qualitatively different. The women had higher scores on the work load and concentration items, and the men had higher scores on the risk demand item.

Table 4. Item bias in relation to gender and age in the items of the stress index and the index for psychosomatic symptoms (total population 1990). ( $X^{2}=$ chi-square, $d f=$ degrees of freedom, bold $=$ significant $P$-value)

\begin{tabular}{|c|c|c|c|c|c|c|}
\hline Index & $x^{2}$ & df & $\underset{P}{\text { Exact }}$ & Gamma & $\underset{P}{\text { Exact }}$ & $\begin{array}{c}\text { Total } \\
\text { number }\end{array}$ \\
\hline \multicolumn{7}{|l|}{ Stress } \\
\hline \multicolumn{7}{|l|}{ Irritable } \\
\hline Gender & 8.7 & 6 & 0.188 & 0.05 & 0.170 & \multirow[t]{2}{*}{5915} \\
\hline Age & 8.7 & 6 & 0.165 & 0.32 & 0.013 & \\
\hline \multicolumn{7}{|c|}{ Concentration difficulty } \\
\hline Gender & 16.9 & 6 & 0.010 & 0.20 & 0.002 & \multirow[t]{2}{*}{5915} \\
\hline Age & 8.5 & 6 & 0.192 & 0.11 & 0.265 & \\
\hline \multicolumn{7}{|l|}{ Forgetful } \\
\hline Gender & 156.3 & 6 & 0.000 & 0.45 & 0.000 & \multirow[t]{2}{*}{5915} \\
\hline Age & 5.5 & 6 & 0.458 & -0.14 & 0.142 & \\
\hline \multicolumn{7}{|l|}{ Depressed } \\
\hline Gender & 8.0 & 6 & 0.225 & -0.12 & 0.052 & \multirow[t]{2}{*}{5915} \\
\hline Age & 12.5 & 6 & 0.058 & -0.00 & 0.517 & \\
\hline \multicolumn{7}{|c|}{ Abnormal tired } \\
\hline Gender & 13.2 & 6 & 0.043 & -0.11 & 0.032 & \multirow[t]{2}{*}{5915} \\
\hline Age & 2.0 & 6 & 0.913 & 0.11 & 0.183 & \\
\hline \multicolumn{7}{|c|}{ Everything overwhelming } \\
\hline Gender & 118.3 & 6 & 0.000 & -0.44 & 0.000 & \multirow[t]{2}{*}{5915} \\
\hline Age & 5.6 & 6 & 0.442 & -0.03 & 0.428 & \\
\hline \multicolumn{7}{|c|}{ Nervous and unbalanced } \\
\hline Gender & 27.6 & 6 & 0.000 & 0.23 & 0.000 & \multirow[t]{2}{*}{5915} \\
\hline Age & 8.3 & 6 & 0.195 & -0.36 & 0.023 & \\
\hline \multirow{2}{*}{\multicolumn{7}{|c|}{ Psychosomatic symptoms }} \\
\hline Headache & & & & & & \\
\hline Gender & 28.2 & 2 & 0.000 & -0.30 & 0.000 & \multirow[t]{2}{*}{5915} \\
\hline Age & 0.5 & 2 & 0.715 & 0.11 & 0.295 & \\
\hline \multicolumn{7}{|c|}{ Stinging, weighting pain in the chest } \\
\hline Gender & 21.2 & 2 & 0.000 & 0.29 & 0.000 & \multirow[t]{2}{*}{5915} \\
\hline Age & 0.9 & 2 & 0.590 & 0.04 & 0.398 & \\
\hline \multicolumn{7}{|c|}{ Bowel movement problems } \\
\hline Gender & 4.6 & 2 & 0.097 & 0.14 & 0.033 & \multirow[t]{2}{*}{5915} \\
\hline Age & 2.9 & 2 & 0.230 & -0.39 & 0.055 & \\
\hline
\end{tabular}


In relation to age, there was no significant bias on the same items. Therefore employees within the same score group had an equal probability of scoring positively regardless of their age.

With respect to the index of autonomy, all 3 items were significantly biased in relation to gender, and 2 items were biased in relation to age. Similar patterns were shown for the remaining indices and items. In relation to gender, all the indices were biased, and most of them were also biased in relation to age and occupational groups. (The results for occupational groups are not shown.) The results also illustrate the increased power of the test based on the partial gamma coefficients compared with the chi-square test. There were several cases in which the gamma coefficients were indisputably significant at the same time as the chi-square statistics were insignificant.

For the outcome indices, the results were also rather clear. Most items in both indices were biased in relation to gender, and 2 of the stress questions were biased also in relation to the age variable (table 4 ). Nevertheless both indices seemed to work better in relation to age groups than in relation to gender. Concerning relations between the stress index, the psychosomatic index, and the occupational group, the bias was extremely significant (table not shown).

It was therefore concluded that the comparisons of the psychosocial work environment for gender, age groups, and occupational groups using these indices are not suitable.

\section{How to proceed?}

There are different ways to proceed to overcome bias problems when the analyses have shown that $\geq 1$ items in an index are biased. One way is to remove the most severely biased item from the index in question and run the analyses again without the item. Another way is to report the results as single-item results instead of using an index construction. A 3rd way is to change the population being analyzed to avoid comparisons of subgroups defined by variables indicating bias.

Removing an item did not seem appropriate in our analysis as most of the items were biased in almost all the indices. Removing 1 item would therefore not be a rational solution.

Reporting single-item results would be a possibility that might turn out to be a relevant procedure. The 3rd strategy, to divide the population into more feasible ones for the intended analysis, was chosen in this special case.

The primary purpose of the study was to construct valid indices to compare the work environment among different occupational groups. In accordance with this intention, the most obvious strategy was to divide the total population into main occupational groups consisting of several occupational groups and then carry out an item-bias analysis again to evaluate whether or not the groups could be compared with respect to their work environment using the proposed index constructions.

The population was divided into occupational groups with not less than 20 respondents in each group. All occupational groups with less than 20 respondents were excluded from further analysis as groups of less than 20 employees were considered too small for statistical analysis. Gender differences within many occupations made gender an important variable in the planned analysis, and therefore the population was divided according to gender. Only occupational groups with either 20 men or 20 women were then included in the population. The remaining population comprised 51 occupational groups consisting of 2715 employees. The occupations were finally grouped according to the main occupational groups in the Danish national classification, a nationally adjusted version of the ISCO- 68 code. Consequently, 9 main occupational groups made up the population for further analysis.

The main groups were nurses ( 5 occupations), teachers (4 occupations), supervisors ( 3 occupations), office clerks or secretaries (7 occupations), shopkeepers or salesmen (3 occupations), cleaners or others ( 7 occupations), mixed group of jobs (4 occupations), skilled metalworkers (4 occupations), and unskilled workers ( 7 occupations).

Item bias was analyzed separately for each group and for all the indices with gender, age, and occupational group as exogenous variables.

Table 5 shows the results of the analyses but only for the main occupational group of teachers and the demand index. Bias was still found in all 3 items in relation to gender. Bias was the most significant in relation to the risk item as male teachers more often than female teachers found that there was a risk of making job errors that resulted in serious consequences. The data showed that especially teachers in technical schools are exposed to this risk, and, as almost all these teachers are men, then the result agrees with the finding of bias for men in general. In relation to all other main occupational groups bias was very limited.

The index of autonomy was only biased a little. Only the work-pace item was a little biased in relation to the occupational group variable. In relation to gender and age there was no bias. The rest of the indices showed very little bias and only to a degree that can be ascribed to statistical chance.

It can be concluded that occupations within each of the main occupational groups can be compared using the indices without restrictions until proved otherwise. To determine whether it was possible to make comparisons among all 9 main occupational groups, we decided to test 
Table 5. Item bias in the items of the demand index for gender, age, and occupational group for the main job group of teachers. ${ }^{\mathrm{a}}$ $\left(\mathrm{X}^{2}=\right.$ chi-square, $\mathrm{df}=$ degrees of freedom, bold $=$ significant $\mathrm{P}$ value)

\begin{tabular}{lrcccc}
\hline Demand index & $\mathrm{X}^{2}$ & df & Exact P & Gamma & Exact P \\
\hline Work load & & & & & \\
$\quad$ Gender & 33.6 & 16 & $\mathbf{0 . 0 0 0}$ & -0.12 & 0.155 \\
Age & 0.0 & 0 & 1.000 & 0.00 & 1.000 \\
Job group & 81.1 & 64 & 0.127 & & \\
Concentration demand & & & & \\
$\quad$ Gender & 19.0 & 15 & 0.183 & 0.37 & $\mathbf{0 . 0 0 2}$ \\
Age & 0.0 & 0 & 1.000 & 0.00 & 1.000 \\
Job group & 70.4 & 60 & 0.188 & & \\
Risk demands & & & & & \\
Gender & 28.0 & 15 & $\mathbf{0 . 0 1 5}$ & -0.47 & $\mathbf{0 . 0 0 0}$ \\
Age & 0.0 & 0 & 1.000 & 0.00 & 1.000 \\
Job group & 86.1 & 60 & 0.055 & & \\
\hline
\end{tabular}

a $1=$ university teachers, $2=$ teachers in primary school, $3=$ teachers in vocational training, $4=$ teachers in leisure-time education.

Table 6. Item bias in the items constituting the demand index in relation to gender, age, and occupational group for nine main occupational groups. ${ }^{a}\left(X^{2}=\right.$ chi-square, $\mathrm{df}=$ degrees of freedom, bold = significant $P$-value)

\begin{tabular}{lrrrrr}
\hline Demand index & $X^{2}$ & $\mathrm{df}$ & Exact $\mathrm{P}$ & Gamma & Exact $\mathrm{P}$ \\
\hline Work load & & & & & \\
Gender & 71.0 & 16 & $\mathbf{0 . 0 0 0}$ & 0.26 & $\mathbf{0 . 0 0 0}$ \\
Age & 64.3 & 64 & 0.382 & 0.13 & $\mathbf{0 . 0 0 0}$ \\
Job group & 98.0 & 64 & $\mathbf{0 . 0 2 5}$ & & \\
Concentration demand & & & & \\
Gender & 56.3 & 14 & $\mathbf{0 . 0 0 2}$ & 0.19 & $\mathbf{0 . 0 0 0}$ \\
Age & 57.8 & 56 & 0.360 & 0.06 & $\mathbf{0 . 0 4 0}$ \\
Job group & 185.9 & 64 & $\mathbf{0 . 0 0 0}$ & & \\
Risk demand & & & & & \\
Gender & 160.5 & 16 & $\mathbf{0 . 0 0 0}$ & -0.43 & $\mathbf{0 . 0 0 0}$ \\
Age & 83.6 & 64 & 0.080 & -0.12 & $\mathbf{0 . 0 0 0}$ \\
Job group & 257.2 & 64 & $\mathbf{0 . 0 0 2}$ & & \\
\hline
\end{tabular}

a 1 health care workers and educators, 2 = teachers, 3 = supervisors, $4=$ office workers, $5=$ shop staff, $6=$ cleaners, $7=$ mixed group,

$8=$ metal workers, $9=$ unskilled workers

whether the indices were biased when the 9 main groups were regrouped into 1 single group and used as the exogenous variable.

Results are only shown for the demand index. There was significant bias for all the items included in the demand index in relation to all 9 main occupational groups (table 6). The conclusion concerning the possibilities to compare the work environment for different groups made earlier is therefore still relevant, namely, a comparison of the work environment among the 9 main occupational groups based on the summated indices as such is not recommended.

\section{Discussion}

Item bias is a relatively new way of analyzing indices used within the fields of medical science, psychology, and sociology $(9,13,14,17)$. Originally the statistical technique was used in psychometrics to determine whether standardized test items behaved identically in different subgroups (eg, ethnicity or gender) drawn from the same population (12).

An important argument for testing indices for item bias is to check the construct validity of the index by testing whether information from the single items is lost when an index is set up. Well-known methods for index construction, like factor analysis, give no clear indication of the information loss that could be the consequence when more items are summated into a single construct. Even if unidimensionality is assumed and tested for the items summated into an index, the construction of the indices is performed without any consideration of the exogenous variables in relation to which they are going to be analyzed.

In our analysis, different populations were analyzed in relation to different exogenous variables, and varying results emerged. When the total population, which is a representative sample of all Danish employees, was analyzed, item bias was rather consistent for all the indices. When the population was reduced to the main occupational groups, item bias almost disappeared. When the main occupational groups were analyzed together, item bias was very consistent again.

The reasons for item bias may be both methodological and substantial. The most frequently occurring methodological problems resulting in item bias are instrument errors due to vaguely and unclearly defined questions or response categories. The mode of data collection has, however, also been known to create problems, especially when different modes of data collection have been used for different parts of the sample (18).

In most cases substantial problems leading to item bias have to do with the fact that different items appear to relate in different ways to certain exogenous variables, a problem that cannot appear for a construct valid set of items. One example of this type of problem has been discussed by Kreiner (19). A set of symptoms included in an index measuring health appeared more frequently with age while another set of items appeared less frequently among elderly people than among the young.

There are several possible substantial explanations for the bias in the total population in the study discussed in this paper. One is the fact that the total population was heterogeneous with respect to $\geq 1$ exogenous variables of importance to some but not necessarily all items. It is reasonable to believe that employing the same indices in occupational groups exposed to very different work environment conditions is rather indecisive. It is obvious that, for example, a blue-collar factory worker and an academic working at a university are exposed to very different psychosocial work environments and that the indices consequently may work differently for such 
groups. It is also probable that persons employed in different occupations perceive the questions differently and that the content of a certain question means something different, depending not only on gender and age but also on socioeconomic background. An assembly-line worker may perceive a question concerning, for example, variation in work quite differently from a university teacher. This possibility leads to the aforementioned question of whether some of the bias in the items was due to unclearly defined questions. This might of course be the case, but it also leads to the question of whether it is possible to construct questions that can be perceived in the same way by people with various socioeconomic backgrounds employed in quite different occupations.

Another reason for the bias disclosed in the total population may be due to the power of the statistical tests. If bias is present, then statistical significance is more easily obtained with large populations than with small ones. No significant bias in relation to the exogenous variables gender, age, and occupational group was found in any of the main occupational groups possibly because it was not as easily demonstrated for small populations as for large ones. However, the analysis was carried out for 9 main occupational groups without any significant results. This finding supports the plausibility of the results.

Another point concerns the fact that, by dividing the population into main occupational groups, each group has become more homogeneous in such a way that it could be expected that people working within the same main occupational group are exposed to similar psychosocial factors. Therefore the indices would be expected to work equally within the group. If one looks at the composition of the single main occupational group, this does, however, not seem to be the case. In almost all the main occupational groups the scores on the indices were significantly different for the occupations constituting the main group (tables not shown). This finding indicates that the groups are not homogeneously exposed to psychosocial factors. There is also another reason to question homogeneity since each main occupational group consists of $\geq 4$ rather different occupations. Teaching at all educational levels is represented in the teacher group. There are teachers from primary schools, teachers from universities, teachers from adult education, and teachers from technical schools. Teaching and contact with pupils or students are common features of their work. However, there is a difference between teaching children in primary schools and teaching adults. The differences probably cause significant differences in the psychosocial exposure of the groups. This possibility is evident in the analysis of the demand index that revealed significant differences among the 4 groups of teachers. More than any other group of teachers, the teachers from technical schools felt that making errors in their jobs could have serious consequences.
Evidently this result does not disagree with the fact that the different teacher groups have the same probability of scoring on the single items in the index. A comparison of the work environment for the different groups constituting the main occupational group is therefore legitimate. For some of the other main occupational groups, the internal differences among the occupations are even greater than they are within the teacher group. In consequence, the explanation that larger homogeneity has caused the bias to disappear is not reliable. Therefore it applies for all 9 main occupational groups that the psychosocial work environment of the occupational groups within every single main group can be compared with each other without problems. Moreover, comparisons can be made also in relation to gender and age within the main occupational groups.

What is the consequence of item bias, and what can be done if there is item bias in the summated indices in relation to an exogenous variable?

If the reasons for bias are purely methodological, the problems have to be rectified. Inadequate items have to be deleted and, if possible, replaced by better-phrased questions or response categories.

As mentioned in the introduction, information from the questions that constitute the index is distorted if there is bias in $\geq 1$ questions in relation to an exogenous variable. It is therefore important to take the context in which the index is being used into consideration. If the study focuses on several exogenous variables, item bias must be examined in relation to each variable, as an index may be biased in relation to only 1 exogenous variable and not to another. Therefore, an index should not be rejected because of item bias in relation to 1 exogenous variable. It may very well be that there is no bias in relation to other variables.

Another way of treating biased indices is to withdraw the most heavily biased items from the index and then check the assumptions of no item bias of the reduced index once again. It is essential to stress that conclusions drawn from analyses of indices containing biased items are neither valid nor reliable and should therefore not be made.

There is, in principle, nothing wrong with a multivariate analysis that includes biased items as separate variables if there are no methodological problems with the items.

Item bias in an index should not be confused with the fact that an index should be able to reveal factual differences in the work environment for the groups being analyzed. On the contrary, item bias only indicates that respondents at the same score group level do not have equal probability of scoring positively on the item.

The discussion of item bias in this paper is based on 2 different considerations. First, item bias has been approached as an item response theory technique that 
focuses on categorical qualitative items rather than the quantitative items or indicators assumed by exploratory and confirmatory factor analysis. Tests for conditional independence between items and exogenous variables may of course be performed for both quantitative and categorical items. However, the technical details will be somewhat different. Instead of chi-square tests and gamma coefficients, standard techniques associated with analyses of variance or analyses by general linear models must be used. Second, the paper has focused on item bias defined with respect to index scales. Items and exogenous variables must be conditionally independent, given the index scale. Item bias may also be defined with respect to the theoretical construct that the index attempts to measure and require that items and exogenous variables be conditionally independent given the latent variable. Item bias in this sense must be analyzed using techniques quite different from those discussed in this paper. Analysis of item bias for quantitative items should, in this case, be addressed by structural equation models. Analysis of the item bias of categorical items should be analyzed either by item response techniques or by structural equation models on the assumption that items are categorized versions of quantitative variables.

The discussion of advantages of different techniques for the analysis of latent variables is a worthwhile and a long-lasting effort. From the point of view of item bias and differential item functioning, we can regard the differences between the competing techniques as strictly technical problems. Irrespective of which type of statistical model one intends to use, it all boils down to tests for conditional independence. The technical details will of course be somewhat different if items quantitatively represent measurement on interval or ratio scales, but the hypotheses to be tested are in principle the same as for categorical items. It is worth noting that an analysis by structural models in general does not lead to or justify the calculation of summary index scales that one can use as proxies for latent variables. Structural modeling will always address the latent variables and the latent structure directly and has no need for summary index scales. For this reason, in most cases, the question of item bias relative to a summary index scale does not even appear in connection with structural modeling.

We finally note that item bias analyses frequently reveal a large number of problems even after purely methodological problems have been identified and corrected. One should regard these results as a catalogue of potential problems associated with the index. A researcher intending to use the index should be aware of these problems, but whether or not they are to be regarded as serious or can be disregarded depends on the purpose of the study. One may argue that bias against variables is not central to the aims of the study, and in many cases it is of no consequence.

\section{References}

1. Caplan R, Cobb S, French J. Job demands and worker health Washington (DC): DHEW (National Institute of OSH), 1975. Report no 45.

2. Berggren T, Hane M, Ekberg K. Stress at work: an interactive model for work environment analyses. In: Zenz $\mathrm{C}$, editor. Occupational medicine: principles and applications. Chicago (IL): Mosby, 1988:1075-86.

3. Karasek RA. Job demands, job decision latitude and mental strain: implications for job redesign. Adm Sci Q 1979; 24:285-308.

4. Karasek RA, Theorell T. Healthy work: stress, productivity, and the reconstruction of working life. New York (NY): Basic Books Inc, 1990.

5. Siegrist J. Adverse health effects of high-effort/low-reward conditions. J Occup Health Psychol 1996;1(1):27-41.

6. Ørhede E. Nordic cooperation in coordinating research on work environment [letter to the editor]. Scand J Work Environ Health 1994;20(1):65-6.

7. Nordic Council of Ministers. Measurement of psychological and social factors at work. Copenhagen: Nordic Council of Ministers, 1995. Nord 39.

8. Nordic Council of Ministers. Review of psychological and social factors at work. Copenhagen: Nordic Council of Minister, 1997. Nord 15.

9. Grønvold M. Validation of a quality of life questionnaire for breast cancer patients. Copenhagen: University of Copenhagen, 1996.

10. Bohrnstedt GW. Measurement. In: Rossi PH, Wright JD, Anderson $\mathrm{AB}$. Handbook of survey research. Orlando (FL): Academic Press, 1983:69-121.

11. Rosenbaum P. Criterion-related construct validity. Psychometrika 1989;54:625-34.

12. Osterlind S. Test item bias. Beverly Hills and London: Sage, 1983. Sage University paper, series on quantitative applications in the social sciences, 30 .

13. Holland PW, Wainer $\mathrm{H}$, editors. Differential item functioning. Hillsdale (NJ): Lawrence Erlbaum, 1993.

14. Bjørner JB, Kreiner S, Ware JE, Damsgaars MT, Bech P. Differential item functioning in the Danish translation of the SF-36. J Clin Epidemiol 1998; Nov 51(11):1189—202.

15. Agresti A. Analysis of ordinal categorical data. New York (NY): Wiley, 1984.

16. Kreiner $\mathrm{S}$. Analysis of multi-dimensional contingency tables by exact conditional tests: techniques and strategies. Scand $\mathrm{J}$ Stat 1987;14:97-112.

17. Ørhede E. Om brugen af surveydata $i$ arbejdsmiljøundersøgelser - et metodestudie [using survey data in studies of the work environment - a methodological study; dissertation; abstract in English]. Copenhagen: National Institute of Occupational Health, 1998.

18. Ooijen Mv, Ivens UI, Johanssen C, Skov T. Comparison of self-administered questionnaire and atelephone interview of 146 Danish waste collectors. Am J Ind Med 1997;31:653-8.

19. Kreiner $S$. Validation of index scales for analysis of survey data: the symptom index. In: Dean K, editor: Linking theory and methods. London, Thousand Oaks, New Delhi: Population Health Research, Sage Publications, 1993:116 - 44.

Received for publication: 15 January 1999 


\section{Appendix}

\section{Questions included in the indices}

\section{Job demands}

Is the amount of work so demanding that you cannot talk or think about anything else during workhours?

Does your work require all your attention and concentration?

If you make an error, does your work tasks involve a health risk or economic risks for your firm?

Response categories

Nearly all the time

$3 / 4$ of the time

$1 / 2$ of the time

$1 / 4$ of the time

Seldom or very little

Never or no

\section{Control}

Can you yourself decide your work pace?

Do you organize your own work (what is to be done, how to do it, and with whom to work)?

Can you decide when your various tasks are to be done (by working faster some days and taking it easier other days)?

Do you get informed about decisions concerning your workplace?

Response categories

Question 1:

Nearly all the time

$3 / 4$ of the time

$1 / 2$ of the time

$1 / 4$ of the time

Seldom or very little

Never or no
Questions 2-4:

Always

Usually

Usually not

Never

\section{Development}

Are your work tasks so difficult that you have to ask someone for advice or help?

Are you able to learn something new and improve your qualifications at work?

Is your work varied?

Does your work require that you repeat the same work tasks many times per hour?

Response categories

Questions 1 and 4:

Nearly all the time

$3 / 4$ of the time

$1 / 2$ of the time

$1 / 4$ of the time

Seldom or very little

Never or no
Question 2:

Always

Usually

Usually not

Never

Question 3:

To a high degree

To some degree

To a small degree

No or only to a very small degree 


\section{Social support from colleagues}

Do you work isolated from your colleagues?

If you need help or advice are you able to obtain it?

Do you get support and encouragement from your colleagues?

Can you talk to your colleagues during workhours?

Response categories

Questions 1-3:

Always

Usually

Usually not

Never

Question 4:

Nearly all the time

$3 / 4$ of the time

$1 / 2$ of the time

$1 / 4$ of the time

Seldom or very little

Never or no

\section{Support from superiors}

Do you get support and encouragement from your superior?

Does it happen that you are praised for the work you have done?

Response categories
Always
Usually
Usually not
Never

\section{Stress}

Do you often feel irritated without any reason?

Do you often find it difficult to concentrate?

Did your closest family tell you that you were forgetful?

Do you often feel sorry and run-down for no reason?

Do you feel abnormally tired?

Have you had a feeling of everything being too much for you within the last 3 months?

Have you felt nervous and unstable within the last 3 months?

Response categories

Questions 1-5:

Yes

Questions 6-7:

No

\section{Psychosomatic symptoms}

Did you, within the last 3 months, feel pain or sting in the upper part of your stomach?

Did you, within the last 3 months, have problems with your bowel movement (diarrhea or constipation)?

Did you, within the last 3 months, have a headache?

Response categories:

Questions 1 and 3:

Yes, every day

Yes, every week

Yes, once a month

No
Question 2:

Yes

No 